\title{
Commentaries
}

\section{Perioperative nutritional support: does it reduce hospital complications or shorten convalescence?}

During the 1960-1970s we learnt how artificial feeding could rescue a few severely undernourished patients. Next, research characterised the integrative biochemistry of illness and sought ways by which the catabolic responses could be influenced nutritionally and hormonally. More recently the large proportion of hospital patients suffering from undernutrition, as judged by both weight for height and by micronutrient status, has become widely appreciated and there has been an interest in more routine supplementation of hospital patients. As the practice of supplementation increases there has been a growing need for randomised controlled trials to assess its clinical effectiveness. But applying rigorous clinical endpoints such as mortality, morbidity, or duration of stay in randomised controlled trials of a secondary treatment such as nutritional support is difficult because the endpoints are easily confounded by primary treatments and other factors.

The physiological effects of undernutrition in the otherwise normal human have been well known for about 50 years. ${ }^{1}$ As far as sip supplements are concerned there is now excellent evidence that they do not simply replace the intake of normal food but effectively increase nutrient intake and improve nutritional status. ${ }^{2}$

Surgeons and gastroenterologists need to know the best nutritional strategies for patients undergoing major abdominal surgery. Preoperative undernutrition has long been known to predict poor surgical outcome. Preoperative feeding can reduce the increased risk of postoperative complications in nutritionally depleted patients. Enteral feeding is at least as good as parenteral feeding in this context ${ }^{3}$ but it is not clear if the time cost of preoperative feeding is justified by its being more effective than early postoperative support. Postoperatively, parenteral feeding should not be used routinely because it increases complication rates in well nourished patients ${ }^{4-6}$ and this technique should be reserved for the severely undernourished and those unable to take nutrients enterally during a prolonged and complicated postoperative course . However, routine very early postoperative enteral feeding of complete polymeric feeds (unlike "immune enhanced" feeds $)^{7}$ has been effective in reducing postoperative complications. ${ }^{8}$ Furthermore, encouraging the intake of sipfeed supplements containing a full and balanced complement of nutrients as the patient begins to eat ${ }^{9}{ }^{10}$ seems to reduce even early postoperative complications whether or not the patient is undernourished. Although undernutrition correlates with length of stay, it may be asking much of a routine nutritional supplement to reduce this given that modern average surgical lengths of stay are little over a week.

In the surgical context sip supplements could benefit the patient not only by reducing postoperative complications and hospital stay but also by speeding recovery after discharge from hospital. One study tested the idea that convalescence might be hastened with sip supplements but was unable to demonstrate such an effect as judged by a "well being" visual analogue score. . In this study postoperative complications and convalescent weight loss were reduced significantly by supplementation.

The randomised controlled trial described by Beattie et $a l$ in this issue of $G u t^{11}$ (page 813) also concentrates on postoperative convalescence. From a total of nearly 2500 patients admitted for elective gastrointestinal or vascular surgery to Ninewells Hospital, Dundee, 450 were screened; 109 were included of whom 101 completed the study and contributed to the results. Patients were either underweight on admission or had lost $5 \%$ or more of their body weight from admission to the eight postoperative day and represented a smaller proportion of undernourished patients than had previously been seen at Ninewells. ${ }^{12}$ On resumption of oral feeding postoperatively, patients were randomised to receive or not to receive a nutritionally complete liquid supplement of $400 \mathrm{ml}$ (600 kcal). Patients continued on the supplements during the remainder of their admission and during convalescence at home for 10 weeks. Antibiotic use was marginally reduced, length of stay (which seems long in this study) was not altered but, most strikingly, patients regained weight much quicker and had improved physical and mental quality of life scores by the end of the study.

The trial deserves close scrutiny. As the authors emphasised, it was not analysed on an intention to treat basis and this will worry some. This group used a body mass index (BMI) of $<20 \mathrm{~kg} / \mathrm{m}^{2}$ (which is close to the fifth centile for an adult British population) or the 15th centile for arm anthropometric measurements. The arm anthropometric inclusion data and the perioperative weight loss criteria contrived to include about $20 \%$ of patients with a BMI above 20. It is not clear whether such patients fared differently from the more clearly undernourished; personal communication from the authors suggests not. The age difference between the groups was unfortunate and may produce some bias.

None the less the study is an important reminder to surgeons of the prolonged impact of surgery on weight and quality of life after discharge from hospital and demonstrates a potential need for continued care as patients move from the surgical ward back to the community. Weight loss in the control group continued for eight weeks (longer by several weeks than was found in the control group of Keele et al's study'), but was reversing at two to four weeks with nutritional intervention.

Much is made of the economical advantages to the NHS of rapid hospital turnover but less often is the economic impact of illness and surgery on the patient. A faster convalescence time should be an important goal for every surgical team, and hospital dietitians linking with community services may be in a position to help deliver this. We can be confident that such an approach will speed up regain in weight, but whether this speeds general convalescence remains a matter of dispute between this study and that of Keele et al.

Head of Rank Department of Human Nutrition,

J POWELL-TUCK

Whitechapel, London E1 1BB, UK

Email:jptuck@mds.qmv.ac.uk 
1 Keys A, Brozek J, Henschel A, Mickelsen O, Taylor H. The biology of human starvation. Minneapolis: University of Minnesota Press, 1950

2 Potter J, Langhorne P, Roberts $M$. Routine protein energy supplementation in adults: systematic review. BMF 1998;317:495-501.

3 von Meyenfeldt MF, Meijerink WJHJ, Rouflard MJ, Buil-Maassen NTHJ, Soeters P. Peri-operative nutritional support-a randomized clinical trial. Clin Nutr 1992;11:180-6.

4 Veterans total parenteral nutrition cooperative study group. Perioperative total parenteral nutrition in surgical patients. N Engl F Med 1991;325:52532.

5 Brennan MF, Pisters PWT, Posner M, Quesada O, Shike M. A prospective randomized trial of total parenteral nutrition after major pancreatic resection for malignancy. Ann Surg 1994;220:436-44.

6 Doglietto GB, Gallitelli L, Pacelli F, et al. Protein-sparing therapy after major abdominal surgery: lack of clinical effects. Ann Surg 1996;223:357-
7 Heslin MJ, Latkany L, Leung D, et al. A prospective, randomized trial of early enteral feeding after resection of upper gastrointestinal malignancy. Amn Surg 1997;226:567-77.

8 Beier-Holgerson R, Boesby S. Influence of postoperative enteral nutrition on post-surgical infections. Gut 1996;39:833-5.

9 Keele AM, Bray MJ, Emery PW, Duncan HD, Silk DBA. Two phase randomised controlled clinical trial of postoperative oral dietary supplements in surgical patients. Gut 1997;40:393-9.

10 Rana SK, Bray J, Menzies-Gow N, et al. Short term benefits of post-operative oral dietary supplements in surgical patients. Clin Nutr 1992;11:337-44

11 Beattie A, Prach AT, Baxter JP, Pennington CR. A randomised controlled trial evaluating the use of enteral nutritional supplements postoperatively in malnourished surgical patients. Gut 2000;46:813-8.

$12 \mathrm{McWhirter} J$, Pennington C. Incidence and recognition of malnutrition in hospital. BMF 1994;308:945-8.

\section{Morphine and biliary pain revisited}

Pain in the biliary tract is assumed to originate from either an obstructive event (the gall bladder contracting on a closed cystic duct, blocked by a gall stone) or inflammation (cholecystitis). Neither situation should be present after the gall bladder is extricated yet pain may persist.

The "post cholecystectomy syndrome" is a poorly defined entity which includes many symptoms that range from the trivial (mild dyspepsia) to severe attacks of abdominal pain and jaundice. ${ }^{1}$ Depending on the original indication for surgery, $20-50 \%$ of patients after cholecystectomy continue to have a variety of non-specific abdominal symptoms such as flatulence and dyspepsia. ${ }^{2-4}$ True biliary type pain occurs as a relatively small percentage (14\%) of symptoms which follow cholecystectomy. ${ }^{5}$ From a different perspective, such pain following cholecystectomy was a complaint in only $0.6 \%$ of men and $2.3 \%$ of women in a household survey. ${ }^{6}$ When symptoms persist following cholecystectomy and no organic basis is evident (from a stricture, retained common duct stone, pancreatitis, tumour, or congenital anomaly) by default the basis becomes "functional". With the gall bladder gone and the bile ducts (which lack a smooth muscle layer) acting as a simple conduit, the sphincter of Oddi (SO) becomes the prime suspect for the pain through spasm or biliary obstruction. The sphincter, strategically located at the junction of the biliary tract, pancreas, and duodenum, is like a mysterious sphinx, an enigma wrapped in a puzzle. Involvement of the SO may take the form of: (1) stenosis (also termed "papillary stenosis") from glandular hyperplasia, muscle hyperplasia/hypertrophy or fibrosis; or (2) dyskinesia due to muscular incoordination or muscular hypertonicity (spasm).

The multinational (Rome II) consensus classified sphincter of Oddi dysfunction into: (a) biliary-type and (b) pancreatic-type. ${ }^{7}$ The diagnostic criteria for SO dysfunction consist of episodes of severe steady pain located in the epigastrium and right upper quadrant in addition to all of the following: (i) episodes lasting 30 minutes or more; (ii) symptoms occurring on one or more occasions over the previous 12 months; (iii) constant pain which interrupts daily activity or requires consultation with a physician and; (iv) no evidence of structural abnormalities to explain the symptoms. Elevated serum aminotransferases, alkaline phosphate, or conjugated bilirubin, and/or pancreatic enzymes (amylase/lipase) support the diagnosis. Although SO dysfunction can exist in the presence of an intact gall bladder, it is more frequently diagnosed following cholecystectomy.

Based on the assumption that these symptoms are caused by abnormal motor function of the SO, the only direct assessment is SO manometry which requires endoscopic retrograde cholangiopancreatography (ERCP). Unfortunately, this invasive procedure is associated with an incidence of up to $24 \%$ of developing pancreatitis. SO manometry, pioneered by Hogan and Geenan from Milwaukee, classified SO dysfunction into three types (table 1) ${ }^{8}{ }^{9}$ These were differentiated according to the presence of objective evidence of biliary obstruction, as identified by: (a) laboratory tests-elevated aminotransferase, alkaline phosphatase, or bilirubin (and for pancreatic SO dysfunction, amylase/lipase); and (b) cholangiographic features - delayed contract drainage and a dilated common duct. The predictability of SO dysfunction and a good response to sphincterotomy varies from a high of $65-95 \%$ in type I to $50-63 \%$ in type II, but decreases to $12-28 \%$ in type III. ${ }^{79}$ The increased likelihood of sphincteric dysfunction in patients with type I has led to the recommendation that manometry is not required; they should proceed directly to endoscopic sphincterotomy. ${ }^{7}$ The Rome II consensus recommended biliary manometry for those with type II and suggested that it be considered in type III.

Dysfunction of the pancreatic sphincter of Oddi differs. Classification into three comparable types is not yet possible. Pancreatic SO dysfunction may be responsible for recurrent pain and pancreatitis with elevated pancreatic enzymes. Manometry of the pancreatic sphincter is necessary for its diagnosis. ${ }^{7}$

There is an obvious need for non-invasive screening criteria to detect dysfunction of the biliary sphincter. Pain provocation tests using morphine with or without prostigmine have limited sensitivity and specificity. ${ }^{10}$ Similarly, the use of a fatty meal or infusion of cholecystokinin to unmask a partially obstructed bile duct on ultrasonography has not gained acceptance. ${ }^{7}$ Because SO tone predominantly regulates bile flow into the duodenum following cholecystectomy, nuclear medicine studies have used radiopharmaceu-

Table 1 Milwaukee classification of biliary sphincter of Oddi dysfunction ${ }^{4}$

\begin{tabular}{|c|c|c|}
\hline Type I & Type II & Type III \\
\hline $\begin{array}{l}\text { Biliary pain plus: } \\
\text { - Delayed drainage of the common bile duct ( }>45 \text { minutes }) \\
\text { - Dilated common bile duct }(>12 \mathrm{~mm} \text { on ultrasound) } \\
\text { Elevated aminotransferase, alkaline phosphatase or bilirubin } \\
\text { ( }>2 \times \text { normal on } 2 \text { occasions })\end{array}$ & $\begin{array}{l}\text { Biliary pain plus } 1 \text { or } 2 \text { of: } \\
\text { Delayed drainage of the common bile duct }(>45 \text { minutes }) \\
\text { - Dilated common bile duct }(>12 \mathrm{~mm} \text { on ultrasound }) \\
\text { - Elevated aminotransferase, alkaline phosphatase or bilirubin } \\
\text { ( }>2 \times \text { normal on } 2 \text { occasions })\end{array}$ & Biliary pain alone \\
\hline
\end{tabular}


tical markers of bile to time their clearance from the biliary tree. Difficulties arise in the presence of intrahepatic cholestasis. Such computer assisted choledochoscintigraphy identifies SO dysfunction as a delayed clearance of marker from the biliary system ${ }^{11}$ or a prolonged transit from the hepatic hilum to the duodenum. ${ }^{12}$ Although the Rome II consensus recommended this as a valid screening test, its precision is less than ideal.

Thomas et al in this issue ${ }^{13}$ (see page 838) used morphine provocation to elicit the hypersensitivity of the dysfunctional SO to opiates and so increase the detection accuracy of biliary scanning. In 34 patients with type II $(n=21)$ or type III ( $n=12)$ SO dysfunction, routine ${ }^{99 m}$ Tc-IDA quantitative biliary scanning could not distinguish between those with normal $(n=16)$ and those with abnormal $(n=18)$ sphincteric tone (abnormal $>40 \mathrm{~mm} \mathrm{Hg}$ ). With low dose morphine provocation $(0.04 \mathrm{mg} / \mathrm{kg}$ intravenously over five minutes), differences became evident with a sensitivity of $83 \%$ and a specificity of $81 \%$. Further, 14 of the 18 patients with abnormal SO manometry experienced biliary pain after morphine compared with two of 16 with normal manometry. Whether or not those patients with positive tests would have benefited from sphincterotomy is unknown as the study did not examine this therapeutic end point.

One must be careful in attributing all biliary-type pain to a motility disorder affecting only the sphincter of Oddi. The abnormality could reside elsewhere as a more generalised motor disorder of the gut, from the oesophagus ${ }^{14}$ through the duodenum-jejunum, ${ }^{15}$ or perhaps as part of the spectrum of the irritable bowel syndrome. ${ }^{16}$ Altered sensation in the form of visceral hypersensitivity is a potential basis for pain in functional gastrointestinal disorders. An abnormal sensitivity to a relatively innocuous stimulus could result from modified receptor sensitivity at the level of the sphincter or adjacent viscus, increased excitability of neurones in the dorsal horn of the spinal cord, and/or altered central modulation of sensory inputs. The bile ducts per se could be the pain trigger zone. ${ }^{17}$ Conversely, a recent study in patients with type III SO dysfunction implicated duodenal hyperalgesia as the basis for the biliary-type pain. ${ }^{18}$ The rich neural connections between the gall bladder and SO, and the biliary tract and the stomach and small intestine orchestrate the interplay between motility and sensitivity of the biliary system and the foregut.

Use of biliary scans with morphine provocation should provide a more effective non-invasive screening test before embarking on manometry and/or sphincterotomy. If combined with barostat-type evaluations of duodenal hypersensitivity, the mystery of the sphincter of Oddi-a motility disorder or a supersensitive sphincter/viscus as the cause of the pain-might be solved.

E A SHAFFER

Professor and Head, Department of Medicine, University of Calgary and Clinical Regional Department Head, Internal Medicine,

Calgary Regional Health Authority and

Department of Medicine, Foothills Hospital,

1403-29th Street NW, Calgary, Alberta T29 T2N, Canada

Email:Eldon.Shaffer@crha-health.ab.ca

1 Ros RE, Zambon D. Post-cholecystectomy symptoms. A prospective study of gall stones. Patients before and two years after surgery. Gut of gall stones.

2 Bates T, Ebbs SR, Harrison M, A'Hern RP. Influence of cholecystectomy on symptoms. Brf Surg 1991;78:964-7.

3 Fenster LF, Lonborg R, Thirlby RC, Traverso LW. What symptoms does cholecystectomy cure? Insights from an outcomes measurement project and review of the literature. Am f Surg 1995;169:533-8.

4 Legoretta AP, Silber JH, Constantino GN, Kobylinski RW, Zatz SL. Increased cholecystectomy rate after the introduction of laparoscopic cholecystectomy. FAMA 1993;270:1429-32.

5 Bar-Meir S, Halpern Z, Bardan E, Gilat T. Frequency of papillary dysfunction among cholecystectomized patients. Hepatology 1984;4:328-30.

6 Drossman DA, Li Z, Andruzzi E, et al. U.S. Householder survey of functional gastrointestinal disorders. Prevalence, sociodemography, and health impact. Dig Dis Sci 1993;38:1569-80.

7 Corazziari E, Shaffer EA, Hogan WJ, et al. Functional disorders of the biliary tract and pancreas. Gut 1999;45(suppl II):48-54.

8 Hogan WJ, Geenen JE. Biliary dyskinesia. Endoscopy 1988;20(suppl 1):17983.

9 Geenen JE, Hogan WJ, Dodds WJ, et al. The efficacy of endoscopic sphincterotomy after cholecystectomy in patients with sphincter of Oddi dysfunction. $N$ Engl f Med 1989;320:82-7.

10 Steinberg WM. Sphincter of Oddi dysfunction: a clinical controversy. Gastroenterology 1988:95:1409-15.

11 Shaffer EA, Hershfield NB, Logan K, et al. Cholescintigraphic detection of functional obstruction of the sphincter of Oddi. Effect of papillotomy. Gastroenterology 1986;90:728-33.

12 Corazziari E, Cicala M, Habib FI, et al. Hepatodudenal bile transit in cholecystectomized subjects. Relationship with sphincter of Oddi function and diagnostic value. Dig Dis Sci 1994;39:1985-93.

13 Thomas PD, Turner JG, Dobbs BR, Burt MJ, Chapman BA. Use of ${ }^{99 \mathrm{~m}} \mathrm{Tc}-$ DISIDA biliary scanning with morphine provocation for the detection of elevated sphincter of Oddi basal pressure Gut 2000;46:000-0.

14 Johnson DA, Cattau EL, Winters C. Biliary dyskinesia with associated high amplitude esophageal peristaltis contractions. Am f Gastroenterol 1986:81: 254-6.

15 Evans PR, Bak Y-T, Dowsett JF, Smith RC, Kellow JE. Small bowel dysmotility in patients with post-cholecystectomy sphincter of Oddi dysfunction. Dig Dis Sci 1997;42:1507-12.

16 Evans PR, Dowsett JF, Bak YT, et al. Abnormal sphincter of Oddi response to cholecystokinin in postcholecystectomy syndrome patients with irritable bowel syndrome. The irritable sphincter. Dig Dis Sci 1995; 40:1149-56.

17 Lasson A, Fork FT, Tragardh B, Zeferfeldt B. The postcholecystectomy syndrome: bile ducts are pain-trigger zone. Scand $\mathcal{f}$ Gastroenterol 1988;23:265-71.

18 Desautels SG, Slivka A, Hudson WR, et al. Postcholecystectomy pain syndrome: pathophysiology of abdominal pain in sphincter of Oddi type III. Gastroenterology 1999;116:900-5. 